\title{
Computer Simulations of EPSP-Spike (E-S) Potentiation in Hippocampal CA1 Pyramidal Cells
}

\author{
John C. Wathey, William W. Lytton, Jennifer M. Jester, and Terrence J. Sejnowski \\ Computational Neurobiology Laboratory, The Salk Institute for Biological Studies, San Diego, California 92186-5800
}

\begin{abstract}
Long-term potentiation of hippocampal excitatory synapses is often accompanied by an increase in the probability of spiking to an EPSP of fixed strength (E-S potentiation). We used computer simulations of a CA1 pyramidal neuron to test the plausibility of the hypothesis that E-S potentiation is caused by changes in dendritic excitability. These changes were simulated by adding "hot spots" of noninactivating voltage-sensitive $\mathrm{Ca}^{2+}$ conductance to various dendritic compartments. This typically caused spiking in response to previously subthreshold synaptic inputs. The magnitude of the simulated E-S potentiation depended on the passive electrical properties of the cell, the excitability of the soma, and the relative locations on the dendrites of the synaptic inputs and hot spots. The specificity of the simulated E-S potentiation was quantified by colocalizing the hot spots with a subset (40 of 80$)$ of the synaptic contacts, denoted "tetanized," and then comparing the effects of the hot spots on these and the remaining (untetanized) synaptic contacts. The simulated E-S potentiation tended to be specific to the tetanized input if the untetanized contacts were, on average, electrically closer to the soma than the tetanized contacts. Specificity was also high if the tetanized and untetanized contacts were segregated to different primary dendrites. The results also predict, however, that E-S potentiation by this mechanism will appear to be nonspecific (heterosynaptic) if the synapses of the untetanized input are sufficiently far from the soma relative to the tetanized synapses. Experimental confirmation of this prediction would support the hypothesis that changes in postsynaptic excitability can contribute to hippocampal E-S potentiation.
\end{abstract}

Principal neurons of the hippocampus exhibit a robust form of synaptic plasticity called long-term potentiation (LTP), in which a brief tetanic stimulus to the afferent fibers causes an enhanced response to subsequent single test stimuli (for review, see Brown

Received June 4, 1991; revised Sept. 25, 1991; accepted Sept. 27, 1991.

This rescarch was supported by NIH National Research Service Award 5 F32 NS08444-02 (J.C.W), an award from the J. Aron Foundation (J.C.W.), NIA Physician Scientist Award 7 K11 AG00382 (W.W.L.), an NIH Biomedical Engineering training grant (J.M.J.), and the Howard Hughes Medical Institute (T.J.S.). We thank Dr. David Amaral for providing the morphological data and Dr. Michael Hines for helpful advice and the use of his CABLE simulation software. Dr. Roberto Malinow first suggested to us the possibility that the modulation of calcium currents in different dendritic branches might exhibit some degree of specificity.

Correspondence should be addressed to John C. Wathey, Computational Neu-

robiology Laboratory, The Salk Institute of Biological Studies, P.O. Box 85800 , San Diego, CA 92186-5800.

Copyright (C) 1992 Society for Neuroscience $0270-6474 / 92 / 120607-12 \$ 05.00 / 0$ et al., 1988). In intracellular recordings this enhancement is measured as an increase in the amplitude or initial slope of the EPSP or as an increase in the probability of firing (Schwartzkroin and Webster, 1975; Abraham et al., 1987; Taube and Schwartzkroin 1988a). The extracellular correlates of these changes are an increase in the initial slope of the population EPSP and an increase in the amplitude of the population spike (Lømo 1971a,b).

In many experiments there is more potentiation of the population spike than can be accounted for by the potentiation of the EPSP. This is most easily seen in the curve relating population spike size to EPSP slope. Typically the effect of LTP is to shift this curve to the left, which indicates that the cell is more likely to fire in response to an EPSP of fixed size (Andersen et al., 1980; Wilson, 1981; Bliss et al., 1983; Abraham et al., 1985, 1987; Kairiss et al., 1987; Chavez-Noriega et al., 1989). This component of LTP is called potentiation of EPSP-to-spike coupling, or simply E-S potentiation (Andersen et al., 1980; for review, see Chavez-Noriega and Bliss, 1991). It represents a change in the responsiveness of the cell to the EPSP, apparently independent of the change in the EPSP itself. In dentate granule cells, E-S potentiation is heterosynaptic, that is, not specific to the tetanized pathway (Abraham et al., 1985). In CA1 pyramidal cells it is homosynaptic (Andersen et al., 1980), although a slowly developing heterosynaptic E-S potentiation has recently been described in CAl (Frey et al., 1988; Reymann et al., 1989).

The mechanisms that have been proposed to account for E-S potentiation fall into two categories: (1) a postsynaptic change that increases the excitability of the cell or (2) an increase in the ratio of synaptic excitation to inhibition (Chavez-Noriega and Bliss, 1991). Several authors have suggested that an increase in postsynaptic excitability would degrade the specificity of LTP and is therefore unlikely to occur in CA1 pyramidal cells (Wilson et al., 1981; Abraham et al., 1987).

In the present study, we have used computer simulations to test the plausibility of localized postsynaptic changes in dendritic excitability as a mechanism for E-S potentiation in CA1 pyramidal neurons. We simulated these excitability changes by varying the density of dendritic voltage-sensitive $\mathrm{Ca}^{2+}$ channels, since there is now direct evidence of active $\mathrm{Ca}^{2+}$ currents in the dendrites of CA1 pyramidal cells (Regehr et al., 1989; Regehr and Tank, 1990). Our main goal was to quantify the effect of such a mechanism on the specificity of LTP. In particular, we have tried to simulate the results of Taube and Schwartzkroin (1988a), who showed with intradendritic recordings that tetanization can increase the probability of firing without significantly changing the size or shape of the EPSP.

Some of these results have been published in abstract form (Wathey et al., 1991). 


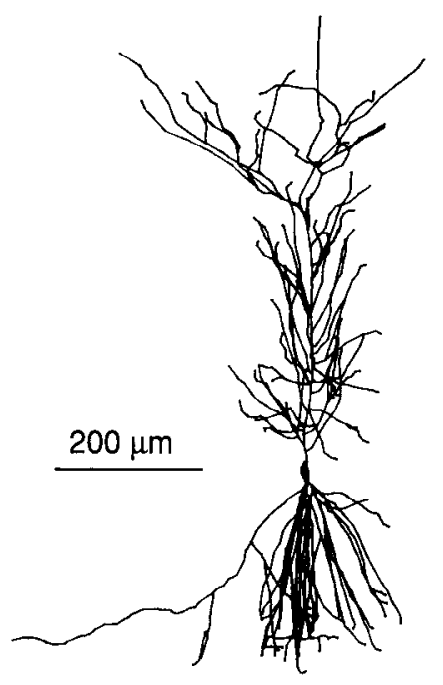

Figure 1. Computer-generated drawing of a CAl pyramidal neuron. The cell was filled in vitro with HRP from an intracellular pipette and digitized from a whole-mount of the slice. The axon is the long process at lower left. The cell has four basal dendrites (below the soma) and one highly branched apical dendrite.

\section{Materials and Methods}

The geometry of our simulated neuron (Fig. 1) was based on a digitized three-dimensional tracing of a pyramidal cell from subfield CAl of the rat hippocampus. This cell was impaled in vitro and filled with HRP by D. Amaral and N. Ishizuka (Salk Institute), who kindly made their data available to us. The neuron was digitized from a $400-\mu \mathrm{m}$-thick whole-mount using the Neuron Tracing System (Eutectic Electronics). Dendritic diameters less than about $1 \mu \mathrm{m}$ could not be accurately measured by the digitizing system; these were arbitrarily set to $1 \mu \mathrm{m}$ for the computer simulations. Dendritic spines were omitted. The neuron had 93 dendritic branches; their total length exceeded $14 \mathrm{~mm}$.

Simulations were done with the compartment model simulator CABLE (Hines, 1989) on a MIPS Magnum 3000 workstation (7 Mflops, 40 Mbytes physical memory). The digitized morphological data were translated to CABLE syntax by a separate computer program. The soma was modeled as a cylinder with both length and diameter equal to $23 \mu \mathrm{m}$. The digitized axon was replaced by an unbranched seven-compartment cylinder $200 \mu \mathrm{m}$ long and $0.9 \mu \mathrm{m}$ in diameter. Each dendritic branch was represented as a series of cylindrical compartments of equal length. The location of each higher-order branch point was adjusted slightly so as to coincide with the end of a compartment of the parent branch. The appropriate average length for the dendritic compartments was determined by repeating the simulations of Figure $2 B$ using different compartment lengths. An average, dendritic compartment length of $36 \mu \mathrm{m}$ (399 dendritic compartments total) was used for all simulations reported here. With 798 dendritic compartments (average length, $\sim 18 \mu \mathrm{m}$ ), the results differed from those of Figure $2 B$ by less than $0.1 \%$. Twelve representative specificity measurements changed by \pm 0.11 or less when the smaller compartment length was used. The time increment was 0.01 msec in most simulations. Halving this time step changed the latency of a typical simulated action potential by $<2 \%$ and its height by $<1 \%$; the effect on nine representative specificity measurements was a change of \pm 0.033 or less in the specificity value.

In all simulations the specific membrane capacitance was $1 \mu \mathrm{F} / \mathrm{cm}^{2}$, and the specific cytoplasmic resistivity was $75 \Omega \cdot \mathrm{cm}$ (Turner, 1984a). In each simulation the specific membrane resistance $\left(R_{m}\right)$ was constant over the entire cell. Most simulations were repeated with $R_{m}=15,600$ and $227,000 \Omega \cdot \mathrm{cm}^{2}$, giving passive input resistances at the soma of 50 and $500 \mathrm{M} \Omega$, respectively. The lower value is typical of measurements taken with impaling microelectrodes (Brown et al., 1981; Turner, 1984a); the larger is commonly obtained in whole-cell patch recordings (Edwards et al., 1989). Some simulations were done using membrane resistances between these two extremes.

The excitatory postsynaptic response was modeled as a conductance increase with a reversal potential of $0 \mathrm{mV}$. The time course was described by an alpha function (Jack et al., 1975) with a peak at $1 \mathrm{msec}$.
The inhibitory response was identical except that the reversalpotential and time to pcak werc $82 \mathrm{mV}$ and $10 \mathrm{msec}$, respectively.

The mechanism of spike generation in hippocampal pyramidal cells is not understood in complete detail, largely because of the technical difficulties involved in voltage-clamping large, fast currents in cells with extensive dendrites (Johnston and Brown, 1983). We therefore used, with slight modification, the equations for fast $\mathrm{Na}^{+}$and $\mathrm{K}^{+}$conductances chosen by Traub (1982) for his model of CA3 pyramidal cells. These conductances were distributed uniformly over the axon, except that their density was greater in the initial segment (the most proximal $5 \mu \mathrm{m}$ ). Most simulations were replicated using three different levels of excitability, achieved by making the soma (1) passive, (2) as excitable as the axon, or (3) as excitable as the axon initial segment. The equations and parameter values are listed in the Appendix.

Modulation of dendritic excitability was simulated by the addition of a persistent voltage-sensitive $\mathrm{Ca}^{2+}$ permeability to various dendritic compartments. The equation used for the $\mathrm{Ca}^{2+}$ current is based on the constant field approximation (Hodgkin and Katz, 1949; Hagiwara and Byerly, 1981). Extra- and intracellular $\mathrm{Ca}^{2+}$ concentrations were held constant at $2 \mathrm{~mm}$ and $50 \mathrm{nM}$, respectively. The equation describing $\mathrm{Ca}^{2+}$ channel activation (see Appendix) is a simplified model that embodies some characteristics of at least two of the $\mathrm{Ca}^{2+}$ channel types known to occur in hippocampal pyramidal cells (Fisher et al., 1990). Its persistence is similar to that of the L-type (high-conductance) channel, and its steady-state activation curve (half-maximal at about $-40 \mathrm{mV}$ ) resembles that of the T-type (low-conductance) channel.

The effect of a change in dendritic excitability was quantified by determining the minimal synaptic strength sufficient to fire the cell, through various synaptic inputs, both before and after the excitability change. The threshold synaptic strength was determined by running a series of trials in which the presynaptic contacts fired in unison at time 0 . In each trial, the synaptic peak conductances and time courses were identical for all synaptic contacts. The simulation ran until the cell either spiked or repolarized following a subthreshold response. After each trial the peak synaptic conductance at all the synaptic contacts was changed to the average of the lowest suprathreshold and highest subthreshold values found up to that point. This binary search procedure continued until the supra- and subthreshold synaptic strengths differed by less than $1 \%$.

In our experience, Hodgkin-Huxley-like models can behave in at least two qualitatively different ways near threshold, depending on the parameter values. In one behavior, which occurs in the original model of the squid axon, spike latency increases and spike height decreases in a graded fashion as the suprathreshold stimulus is reduced toward threshold. In this case threshold must be defined by some arbitrary criterion based on spike height. In the other behavior, which occurs in the present model, spiking is truly all-or-none, regardless of proximity to threshold, but spike latency increases without bound as threshold is approached. Spikes elicited within our $1 \%$ threshold criterion came at latencies of up to $2 \mathrm{sec}$ (simulated time) when the highest value of membrane resistance was used. These unphysiologically long latencies presumably result from the continuous nature of the differential equations used to model the spike and from the absence of noise in the membrane potential (Lecar and Nossal, 1971). To judge the effects of these long latencies on our results, we repeated some of the simulations summarized in Figure 6 using the criterion that any spike at a latency greater than 100 msec was considered a subthreshold response. The results (not shown) were qualitatively similar to those of Figure 6 , although the less accurate criterion for threshold introduced greater scatter in some specificity plots.

The specificity of the simulated E-S potentiation was measured by comparing the reduction in threshold synaptic strength at two groups of synaptic contacts denoted "tetanized" and "untetanized" (see Results). Each group comprised 40 synaptic contacts distributed randomly, either over the entire dendrite or over a portion of it delimited by arbitrary proximal and distal boundaries. A pseudorandom number generator was used to choose the synapse locations (Press et al., 1988).

\section{Results}

\section{Passive properties}

Figure 2 summarizes the steady-state passive properties of the simulated neuron. The rate of decay of potential with distance (Fig. $2 B$ ) is mainly determined by the density of dendritic branches, in agreement with the findings of Turner (1984b). Passive charging curves (not shown) indicate time constants at 

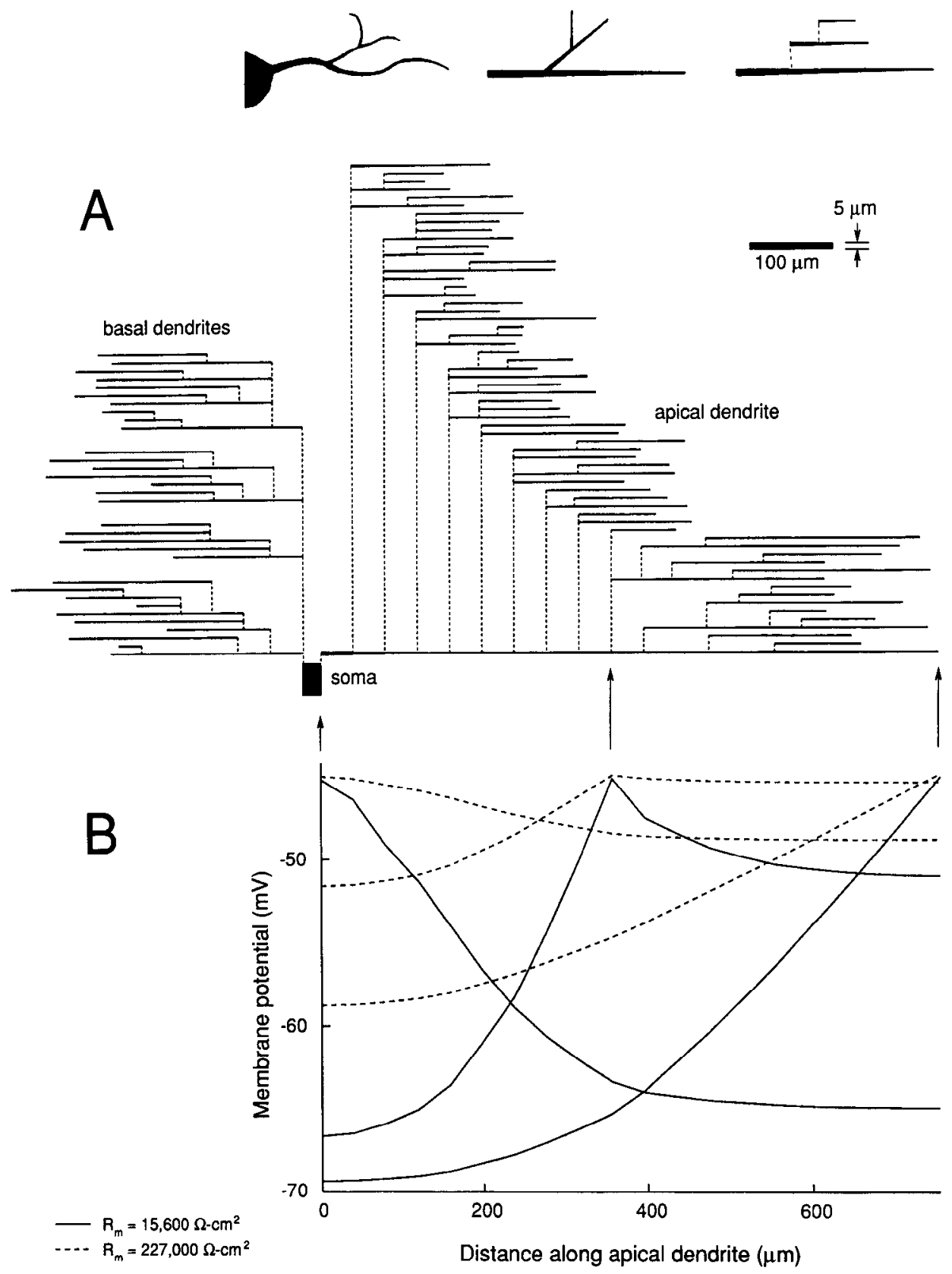

Figure 2. A, Schematic diagram of the branching pattern of the cell in Figure 1 . The drawing at the top shows how such diagrams are derived from the actual dendritic structure. Horizontal lines show the lengths and diameters of the dendritic branches at different scales as indicated by the scale bar. The broken vertical lines only show connectivity and do not represent part of the dendrite. $B$, Steady-state membrane potential responses to continuous current injection into the soma or various sites along the primary apical dendrite. The abscissa shows distance along the dendrite at the same scale as in $A$. The entire cell was passive, and the resting potential was $-70 \mathrm{mV}$. Each curve represents a separate simulation run. The maximum of each curve indicates the location of the current injection (arrows). Solid and broken lines show results from cells having specific membrane resistances of 15,600 and $227,000 \Omega \cdot \mathrm{cm}^{2}$, respectively. The amount of current was adjusted to compensate for differences in input resistance and varied from $0.5 \mathrm{nA}$ at the soma to $0.063 \mathrm{nA}$ at the distal tip of the low-resistance cell. The corresponding range was 0.05 to $0.027 \mathrm{nA}$ for the high-resistance cell. Note the more rapid decay of potential with distance in the proximal half of the dendrite, where the density of secondary dendritic branches is greatest.

the soma of $12 \mathrm{msec}\left(R_{m}=15,600 \Omega \cdot \mathrm{cm}^{2}\right)$ or $214 \mathrm{msec}\left(R_{m}=\right.$ $\left.227,000 \Omega \cdot \mathrm{cm}^{2}\right)$.

\section{$E-S$ potentiation}

Using intradendritic recordings in CAl, Taube and Schwartzkroin (1988a) found that a tetanus to the afferent fibers sometimes causes an increase in the probability of firing with no change in the size or shape of the EPSP. In one such experiment (their Fig. 4), they recorded responses to single-shock test stimuli before and after the tetanus and found that the previously subthreshold EPSP consistently evoked a spike after the tetanus. They compared the pre- and posttetanus EPSPs by blocking the spikes with hyperpolarizing current.

We simulated this experiment (Fig. 3) by assuming that the effect of the tetanus is to upregulate a voltage-sensitive $\mathrm{Ca}^{2+}$ permeability in the postsynaptic cell. In this simulation the soma was as excitable as the axon initial segment, and the dendrites were initially passive. The specific membrane resistance was $20,000 \Omega \cdot \mathrm{cm}^{2}$. The excitatory input comprised 18 synaptic contacts onto secondary apical dendritic branches, 180-280 $\mu \mathrm{m}$ from the soma. The maximal EPSP conductance at each contact was $2.5 \mathrm{nS}$, equivalent to one or a few quantal conductances (Brown et al., 1979; Higashima et al., 1986; Turner, 1988; Bekkers and Stevens, 1989). The feedforward IPSP was simulated by 14 synaptic contacts onto secondary apical branches (140$300 \mu \mathrm{m}$ from the soma), each with a peak conductance of 2.5 $\mathrm{nS}$. The onset of the IPSP came at a latency of $2 \mathrm{msec}$ following the onset of the EPSP. Responses to synaptic stimuli were monitored from the primary apical dendrite, about $80 \mu \mathrm{m}$ from the soma, to simulate intradendritic recording. A single stimulus to these 32 afferent inputs evoked a subthreshold synaptic potential (Fig. $3 A$ ); the response became suprathreshold with the addition of one more excitatory synaptic contact (not shown).

The potentiating effect of tetanic stimulation was then sim- 

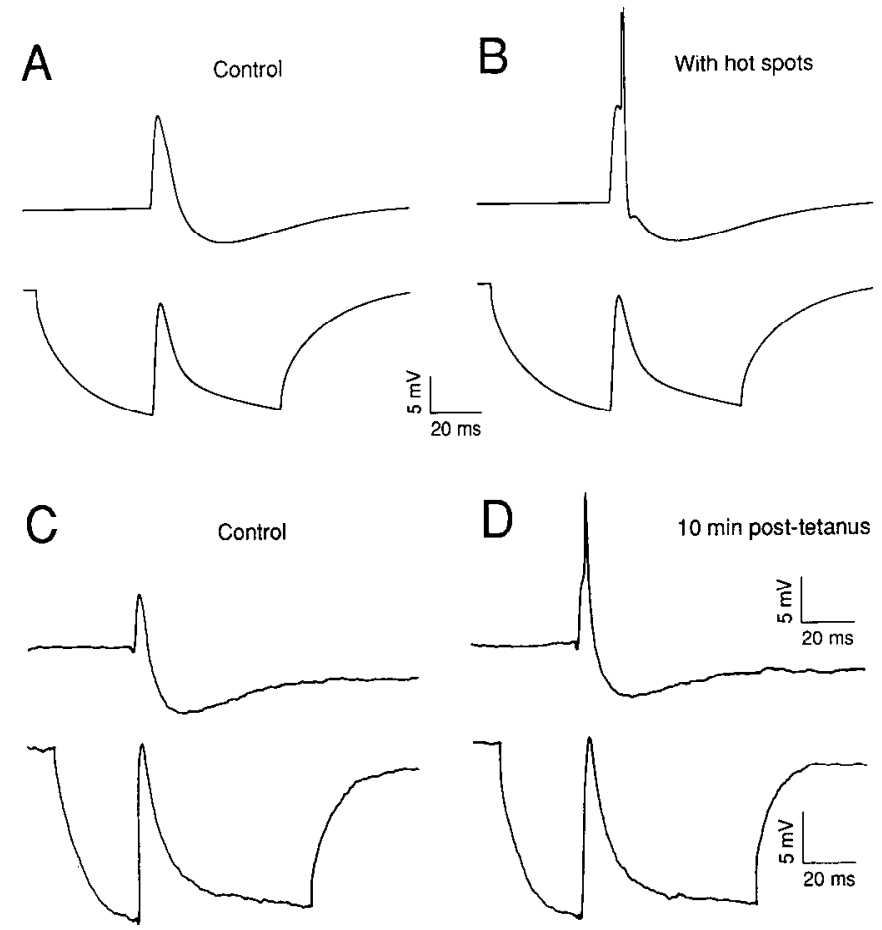

Figure 3. Simulation of an intradendritic recording showing E-S potentiation. $A$, A test shock that excites 18 excitatory and 14 inhibitory synaptic contacts on the apical dendrite produces a subthreshold EPSP (upper trace). Here and in $B$, the lower trace shows the response embedded in a $0.3 \mathrm{nA}$ hyperpolarizing current pulse. $B$, Tetanic stimulation is assumed to increase dendritic excitability by the addition of voltagesensitive $\mathrm{Ca}^{2+}$ permeability near the tetanized synaptic contacts. This results in E-S potentiation: the test stimulus has become suprathreshold (upper trace), but the EPSP is unchanged (lower traces in $A$ and $B$ ). $C$ and $D$, Portions of Figure 4 of Taube and Schwartzkroin (1988a), reproduced with permission, for comparison with the simulation results in $A$ and $B$. In $C$, a test shock in stratum radiatum elicits a subthreshold response in an intradendritic recording from a CA1 pyramidal cell. In $D$, following tetanization of this synaptic input, the response to the same test shock is suprathreshold. Embedding each response in a $0.5 \mathrm{nA}$ hyperpolarizing current pulse ( $C$ and $D$, lower traces) shows that the EPSP was not significantly altered by the tetanus.

ulated by adding a voltage-sensitive $\mathrm{Ca}^{2+}$ permeability to each of the 18 dendritic compartments receiving excitatory input. For convenience we refer to such a localized area of excitable membrane as a dendritic "hot spot." The maximum $\mathrm{Ca}^{2+}$ permeability was $0.4 \mu \mathrm{m} / \mathrm{sec}$ for each of the 18 hot spots. This increase in dendritic excitability made the previously subthreshold input suprathreshold (Fig. $3 B$, upper trace). When the response was embedded in a $0.3 \mathrm{nA}$ hyperpolarizing current step, spiking was blocked, and the EPSP was virtually identical to the control EPSP (Fig. $3 A, B$, lower traces).

During the spike, the peak fraction of open $\mathrm{Ca}^{2+}$ channels was 0.15 , and the peak $\mathrm{Ca}^{2+}$ current was $9 \mu \mathrm{A} / \mathrm{cm}^{2}$. Assuming that 10 open channels $/ \mu \mathrm{m}^{2}$ yield a current of about $100 \mu \mathrm{A} / \mathrm{cm}^{2}$ (Hille, 1984, p 221), one hot spot comprises about 690 channels in a dendritic compartment of area $115 \mu \mathrm{m}^{2}$. The total $\mathrm{Ca}^{2+}$ channel density in the hot spot is therefore about 6 channels/ $\left.\mu \mathrm{m}^{2}\right)$.

Taube and Schwartzkroin (1988a) also found that E-S potentiation had no significant effect on threshold as measured by injection of depolarizing current through the intradendritic electrode. In the simulation of Figure 3, the increase in dendritic excitability caused only a $0.6 \%$ decrease in threshold to injected current.

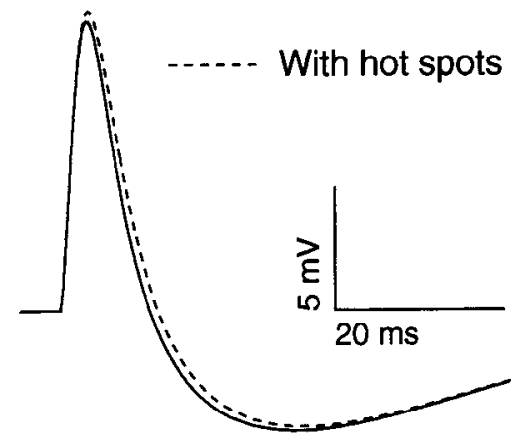

Figure 4. Effect of $\mathrm{Ca}^{2+}$ channel activation on the EPSP. The simulations of Figure 3, $A$ and $B$ (upper traces), are here repeated and superimposed with the soma and axon made passive to eliminate spiking. Calcium channel activation causes the EPSP to rise to a slightly greater peak at a longer latency (broken curve) than does the control EPSP (solid curve).

A small effect of $\mathrm{Ca}^{2+}$ channel activation on the shape of the EPSP can be seen if spiking is blocked, not by hyperpolarization as in Figure 3, but instead by omitting the active membrane properties of the soma and axon (Fig. 4).

These simulations show that local changes in dendritic excitability can explain the E-S potentiation observed by Taube and Schwartzkroin (1988a), but they leave unanswered an important question: to what extent do these changes affect other synaptic inputs elsewhere on the dendrites?

\section{Specificity of $E-S$ potentiation}

To address this question we ran additional simulations involving two groups of synaptic inputs at different locations on the dendritic tree (for simplicity, only excitatory synapses were used in these simulations). The "tetanized" group was equivalent to the synaptic contacts in the simulations of Figure 3 , in that hot spots could be added at the sites of these contacts. The strength of this group of synapses was first adjusted, in the absence of hot spots, to a subthreshold value $(10 \%$ below the synaptic strength required to fire the cell). The second group of synaptic contacts ("untetanized") was then adjusted in strength to be just barely subthreshold (within 1\%); the tetanized inputs were inactive during this adjustment. At this point hot spots were added to the compartments receiving tetanized contacts. The maximum $\mathrm{Ca}^{2+}$ permeabilities of the hot spots were adjusted such that they were just sufficient to make the tetanized input suprathreshold (i.e., just sufficient to cause E-S potentiation). Typically the addition of hot spots near the tetanized contacts also made the untetanized input suprathreshold. This lack of specificity is not surprising, since the untetanized inputs were nearly at threshold before the hot spots were added. Of greater importance is the degree to which specificity was affected. The loss of specificity was quantified by reducing the synaptic strength of the untetanized input until it was again subthreshold.

This percentage decrease in threshold synaptic conductance at the untetanized input $(\Delta U /)$ gives a measure of the specificity of E-S potentiation when compared to the effect of the hot spots on the tetanized input. A convenient way to make this comparison is as follows:

$$
S=(\Delta T-\Delta U) /(\Delta T+\Delta U),
$$

where $S$ is the specificity of E-S potentiation and $\Delta T$ is the percentage reduction in threshold synaptic strength of the tetanized input caused by the addition of hot spots. Using the protocol described above, $\Delta T$ is always $10 \%$. With this defini- 

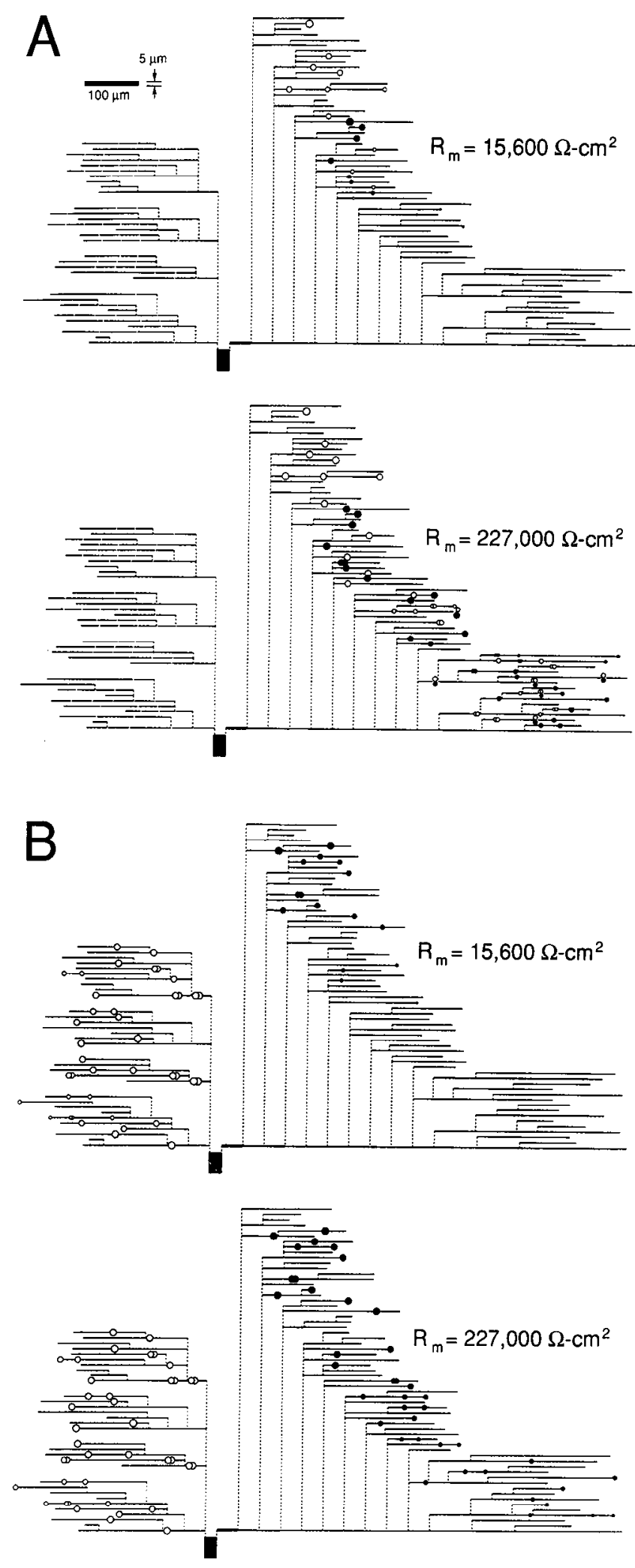

Figure 5. Representative locations of synaptic contacts used in specificity tests (Figs. 6-9). Open and solid circles indicate tetanized and untetanized inputs, respectively. For each such pattern of synapse locations, a second measure of specificity was obtained with the roles of the tetanized and untetanized contacts exchanged. The size of each circle indicates the contribution of that synaptic contact to the total response, measured as the percentage decrease in total EPSP height (measured in the soma) caused by deleting that contact. These synaptic strengths were determined for two different membrane resistances, as indicated. $A$. tion, specificity approaches 1 if the effect of hot spots on the tetanized input is much larger than on the untetanized and approaches -1 if the effect on the untetanized input is larger; it is 0 if both inputs are equally affected.

In the first series of these simulations, the two groups of synapses were distributed randomly over secondary and higherorder branches of the apical dendrite, with 40 synaptic contacts in each group. Figure $5 A$ shows one of the nine different patterns of synaptic contacts used. Hot spots were added to those compartments receiving a tetanized contact (a few of which also received contacts from the untetanized group). For each such pattern, specificity was first measured with one group (e.g., the open circles in Fig. $5 A$ ) serving as the tetanized input and the other as the untetanized. Then a second measurement was obtained by exchanging the roles of the two groups (e.g., the solid circles in Fig. $5 A$ would become the tetanized group). In this way the nine spatial patterns of synaptic input produced the 18 data points in each panel of Figure 6 .

Specificity varied from -0.69 to 0.86 , depending on the locations of the synapses and on membrane resistance and excitability of the soma (Fig. 6). The strength of the hot spots (measured as the peak $\mathrm{Ca}^{2+}$ permeability added to each compartment receiving a tetanized contact) ranged from 0.020 to $0.98 \mu \mathrm{m} /$ sec. The occurrence of negative specificity in some of these simulations was surprising: since the hot spots were always colocalized with tetanized contacts, it seemed paradoxical that they could, in some cases, have a greater effect on the untetanized input. This phenomenon appeared to be related to the relative electrical distances of the tetanized and untetanized inputs from the soma, as judged by their effectiveness at firing the cell. To quantify this effect we define a "distance index," $D$ :

$$
D=\left(\theta_{T}-\theta_{U}\right) /\left(\theta_{T}+\theta_{U}\right),
$$

where, in the absence of hot spots, $\theta_{T}$ and $\theta_{U}$ are the synaptic strengths just sufficient to fire the cell via the tetanized and untetanized inputs, respectively. The distance index approaches 1 if the untetanized input is closer to the soma than the tetanized $\left(\theta_{T}>\theta_{U}\right)$ and approaches -1 if the tetanized input is closer; it is 0 if the two inputs are equidistant from the soma (i.e., equally effective at firing the cell). A correlation between $S$ and $D$ is evident in Figure 6: E-S potentiation tends to be homosynaptic (specific) if the untetanized input is closer to the soma than the tetanized input; otherwise, the effect is heterosynaptic. The correlation appeared with all combinations of membrane resistance and somatic excitability tested (Fig. 6), although the ranges of $S$ and $D$ values decreased as membrane resistance and somatic excitability increased.

The correlation even persisted when the hot spots were added to the proximal part of the dendrites, rather than to the sites of the tetanized contacts. Figure 7 shows the results of simulations identical to those of Figure 6, except that the hot spots were added to the most proximal $80 \mu \mathrm{m}$ (two compartments) of each

$\leftarrow$

Both inputs are intermingled on the apical dendrite, but the tetanized contacts are, on average, closer to the soma than the untetanized contacts. For the low-resistance cell (upper panel), the largest solid and open circles represent reductions in EPSP height of $6.3 \%$ and $2.7 \%$, respectively, when those contacts are omitted; the corresponding values are $3.1 \%$ and $2.6 \%$ for the high-resistance cell (lower panel). $B$, The tetanized and untetanized inputs are segregated to the apical and basal dendrites, respectively. The largest solid and open circles represent reductions in EPSP height of $9.2 \%$ and $8.9 \%$, respectively (upper panel). In the lower panel, the largest circles indicate a $3.2 \%$ reduction for both groups of synapses. 
Figure 6. Specificity of E-S potentiation for 18 different spatial distributions of synaptic input on the apical dendrite (as in the example of Fig. 5A). "Hot spots" of voltage-sensitive $\mathrm{Ca}^{2+}$ permeability were added to those compartments receiving tetanized contacts, such that the threshold for firing the cell via the tetanized input was reduced $10 \%$. Specificity (ordinate) is a measure of the effect of these hot spots on the untetanized input. Positive values indicate a greater effect on the tetanized than on the untetanized input; 0 indicates equal effect on the two inputs; negative values indicate a greater effect on the untetanized than on the tetanized input. The distance index (abscissa) is a measure of the relative electrical distances of the tetanized and untetanized inputs from the soma, as judged by their effectiveness at firing the cell. Positive values indicate that the untetanized input is closer than the tetanized input; negative that the two inputs are equidistant from the soma. The simulations were repeated using different membrane resistances and different levels of excitability of the soma, as indicated. E-S (specific) if the untetanized input is closer to the soma than the tetanized input; otherwise the effect is heterosynaptic. Solid symbols indicate the results obtained using the pattern of synapse locations shown in Figure $5 A$. values indicate the reverse; 0 indicates potentiation tends to be homosynaptic
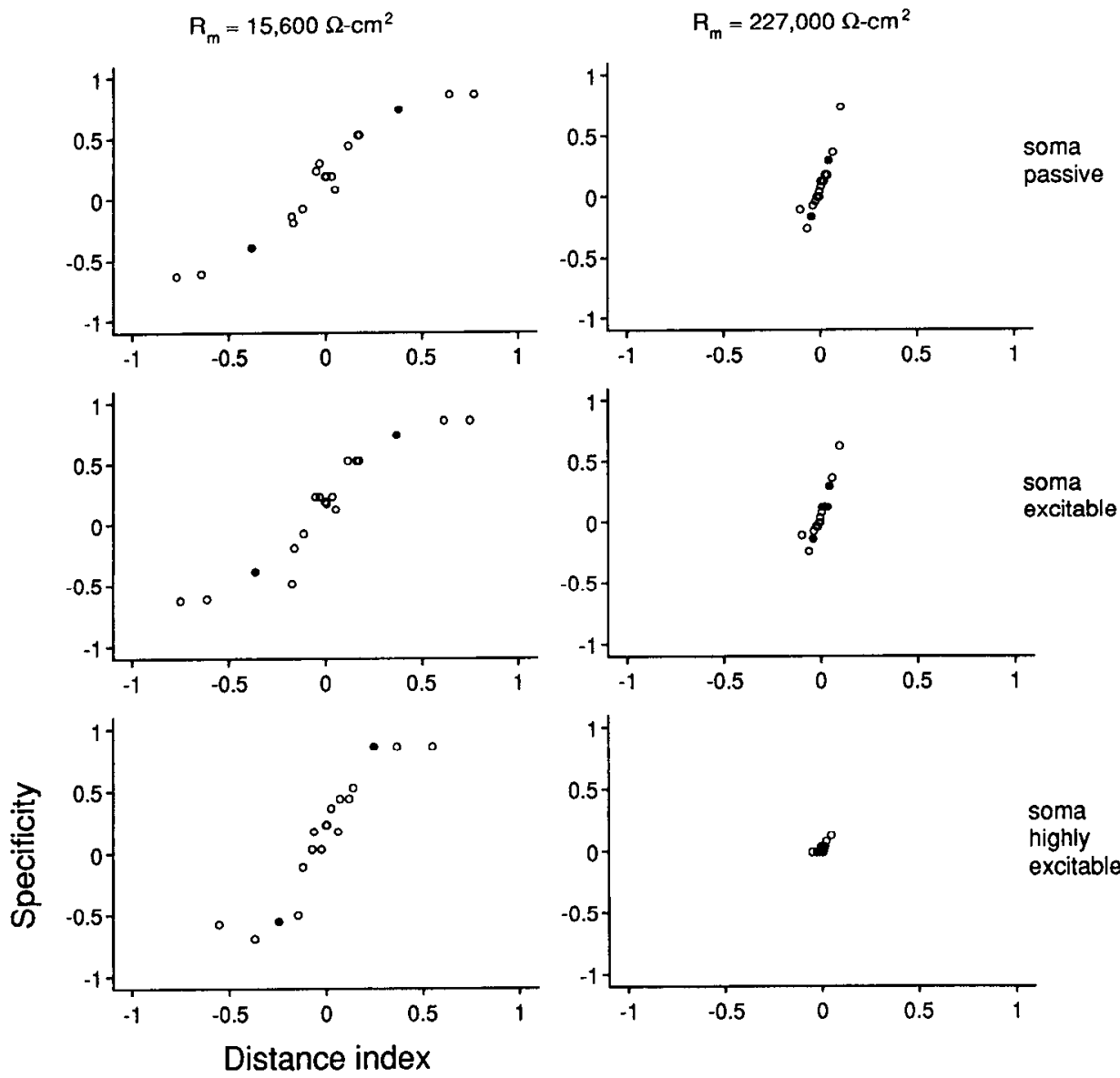

of the five primary dendrites. Specificity varied from -0.47 to 0.52 ; hot spot strength ranged from 0.073 to $1.4 \mu \mathrm{m} / \mathrm{sec}$. For each distance index value, the magnitude of the specificity (whether positive or negative) was less than in Figure 6.

In another series of simulations the tetanized and untetanized inputs were segregated: one group was confined to the apical and the other to the basal dendrites. Figure $5 B$ shows one of the eight different patterns of synaptic contacts used. As explained above, each specificity measurement was repeated with the roles of the two groups of synapses exchanged. Hot spots were added to those compartments receiving a tetanized contact. Specificity varied from -0.24 to 1.0 (Fig. 8); the strength of the hot spots ranged from 0.091 to $0.91 \mu \mathrm{m} / \mathrm{sec}$. The specificity of E-S potentiation was greater, over a broader range of distance index values, than in the simulations of Figure 6. Even so, it was nonspecific when the untetanized input was sufficiently far from the soma relative to the tetanized input.

Figure 9 shows the results of simulations identical to those of Figure 8, except that the hot spots were added to the proximal part of the dendrites, rather than to the sites of the tetanized contacts. Specificity varied from -0.54 to 0.62 ; hot spot strength ranged from 0.092 to $1.6 \mu \mathrm{m} / \mathrm{sec}$. Specificity was near zero over a wide range of distance index values, but for most combinations of membrane resistance and somatic excitability, specificity increased with increasing distance index.

The correlation between specificity and distance index, and the paradoxical "negative specificity" seen in some simulations suggest that distal synaptic inputs might be disproportionately more sensitive to changes in excitability of the cell than are more proximal inputs. The simulations of Figure 10 examined this hypothesis in a more direct way. Each graph shows the results of 20 separate simulation runs. In each of these, a single excitatory synaptic contact was placed on the soma or on one of the 19 compartments of the primary apical dendrite. The peak synaptic conductance just sufficient to fire the cell via that one contact was then measured and plotted for these 20 locations. The procedure was repeated for different combinations of membrane resistance and somatic excitability. For most of these combinations, the graph of threshold synaptic strength approached a vertical asymptote, beyond which a single synaptic contact could not fire the cell. In all cases the slope of the curve tended to increase with distance from the soma. When hot spots wcre added to the proximal dendrites, a disproportionately greater decrease in threshold occurred in the more distal parts of the threshold curve (Fig. 10, broken lines). The hot spots used here were identical in strength and location to those in one of the simulations of Figure 7 for which the distance index was nearly zero. The hot spot strengths are listed on the figure.

\section{Discussion}

\section{Limitations of the model neuron}

Hippocampal pyramidal neurons have at least a dozen different voltage-sensitive conductances that act over a wide range of voltages and time scales (Llinás, 1988; Fisher et al., 1990). We have omitted most of these from our model for three reasons. First, for many of these conductances, the voltage clamp data are not sufficient for a detailed mathematical model of their kinetics, and little is known about their spatial distribution on 
$R_{m}=15,600 \Omega-\mathrm{cm}^{2}$
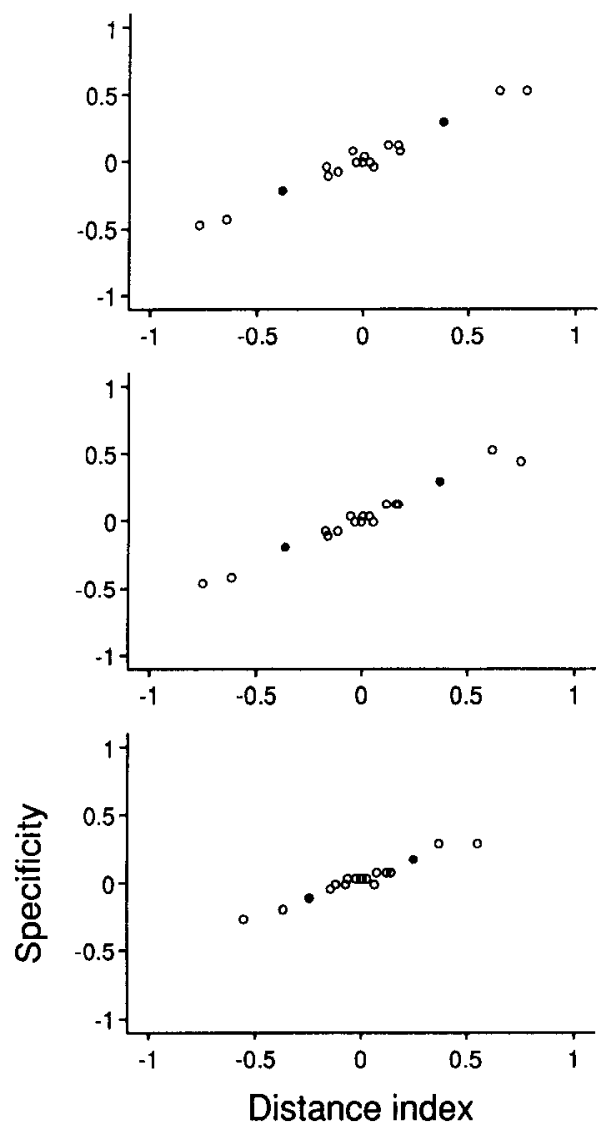

$R_{m}=227,000 \Omega-\mathrm{cm}^{2}$
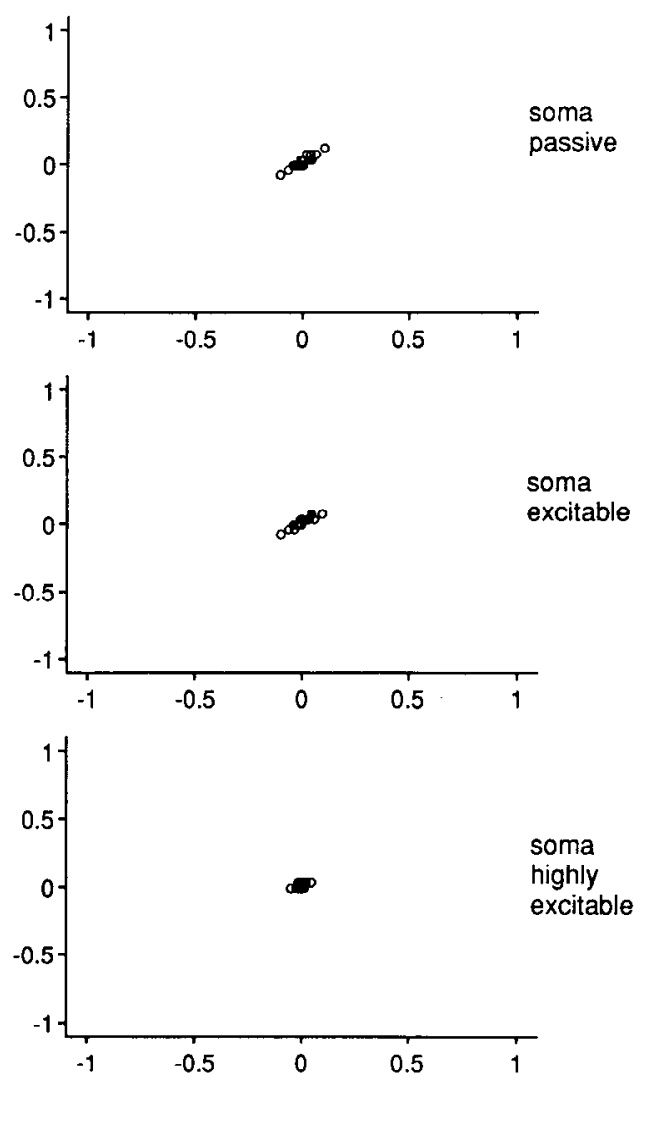

Figure 7. Same as Figure 6, except that the hot spots were added to the most proximal $80 \mu \mathrm{m}$ of the five primary dendrites, rather than to the sites of the tetanized synaptic contacts. As in Figure 6, specificity and distance index appear to be correlated, although each point is closer to 0 specificity than is the corresponding point in Figure 6. the cell. Second, modeling the neuron with its full complement of conductances would be prohibitively time consuming. The specificity measurements (Figs. 6-9) required weeks of computer time, even with our simplifications. Third, our goal was not to reconstruct the complete behavior of a pyramidal cell, but was instead to determine, in broad outline, the effect of changes in dendritic excitability on the specificity of E-S potentiation as measured with various spatial distributions of synaptic input.

In view of these limitations, we have explored the behavior of the model over wide ranges of membrane resistance and somatic excitability, with many different patterns of synapse locations. Our principal finding, the correlation of specificity with distance index, is robust in that it persists throughout these variations.

Although our model uses increases in $\mathrm{Ca}^{2+}$ currents to simulate E-S potentiation, similar results could almost certainly have been obtained using increases in $\mathrm{Na}^{+}$currents or decreases in $\mathrm{K}^{+}$or $\mathrm{Cl}^{-}$or currents.

\section{Two mechanisms for $E$-S potentiation}

There is considerable evidence in the literature that an increase in excitation relative to feedforward inhibition contributes to E-S potentiation, at least in CA1. Tetanic stimulation sometimes changes the shape of the postsynaptic potential (PSP) such that a PSP of a given slope reaches a higher peak at a greater latency (Abraham et al., 1987). This is most simply explained as greater potentiation of the EPSP than of the feedforward IPSP, since the IPSP begins slightly after the onset of the EPSP and contributes little to the EPSP initial slope. Furthermore, picrotoxin mimics the effects of E-S potentiation, shifting the E-S curve to the left, and prevents additional, tetanus-induced leftward shifts (Abraham et al., 1987; Chavez-Noriega et al., 1989).

This mechanism cannot, however, explain results in which the probability of firing is potentiated with no change in the EPSP (Bliss and Lømo, 1973; Schwartzkroin and Webster, 1975; Frey et al., 1988; Taube and Schwartzkroin, 1988a). Such results could be explained by a decrease in inhibition (either tonic or feedforward), but though there is some evidence for a decrease in inhibition with LTP (Haas and Rose, 1982; Abraham et al., 1987), most studies find either no change or a slight increase in inhibition following the tetanus (Haas and Rose, 1984; Griffith et al., 1986; Kairiss et al., 1987; Taube and Schwartzkroin, 1987). An alternative is that a component of E-S potentiation is caused by an increase in the intrinsic excitability of the postsynaptic cell. Using current-source density analysis in CA1, Taube and Schwartzkroin (1988b) identified a short-latency dendritic current sink that in some experiments shifted distally about $30 \mu \mathrm{m}$ after LTP induction. They suggest that a voltagesensitive $\mathrm{Ca}^{2+}$ current might underlie this current sink and that a persistent change in this current, evidenced by the shift in the current sink, might account for E-S potentiation.

Other lines of evidence also suggest that E-S potentiation can occur by a mechanism independent of that which underlies the synaptic component of LTP. Brief exposure of CA1 pyramidal cells to low-glucose medium reduces the orthodromic population spike without affecting the EPSP or the antidromic population spike (Fan et al., 1988), suggesting a specific vulnerability of an E-S coupling mechanism. The early, homosynaptic com- 
Figure 8. Same as Figure 6, except that the tetanized and untetanized inputs are segregated to dendrites on opposite sides of the soma (as in the example of Fig. $5 B$ ). Sixteen different spatial distributions of synaptic input were used. Hot spots were added to those compartments receiving tetanized contacts. In this case, E-S potentiation is highly specific over a wide range of distance index values. It still becomes nonspecific, however, when the untetanized input is sufficiently far from the soma relative to the tetanized input. Solid symbols indicate the results obtained using the pattern of synapse locations shown in Figure $5 B$.
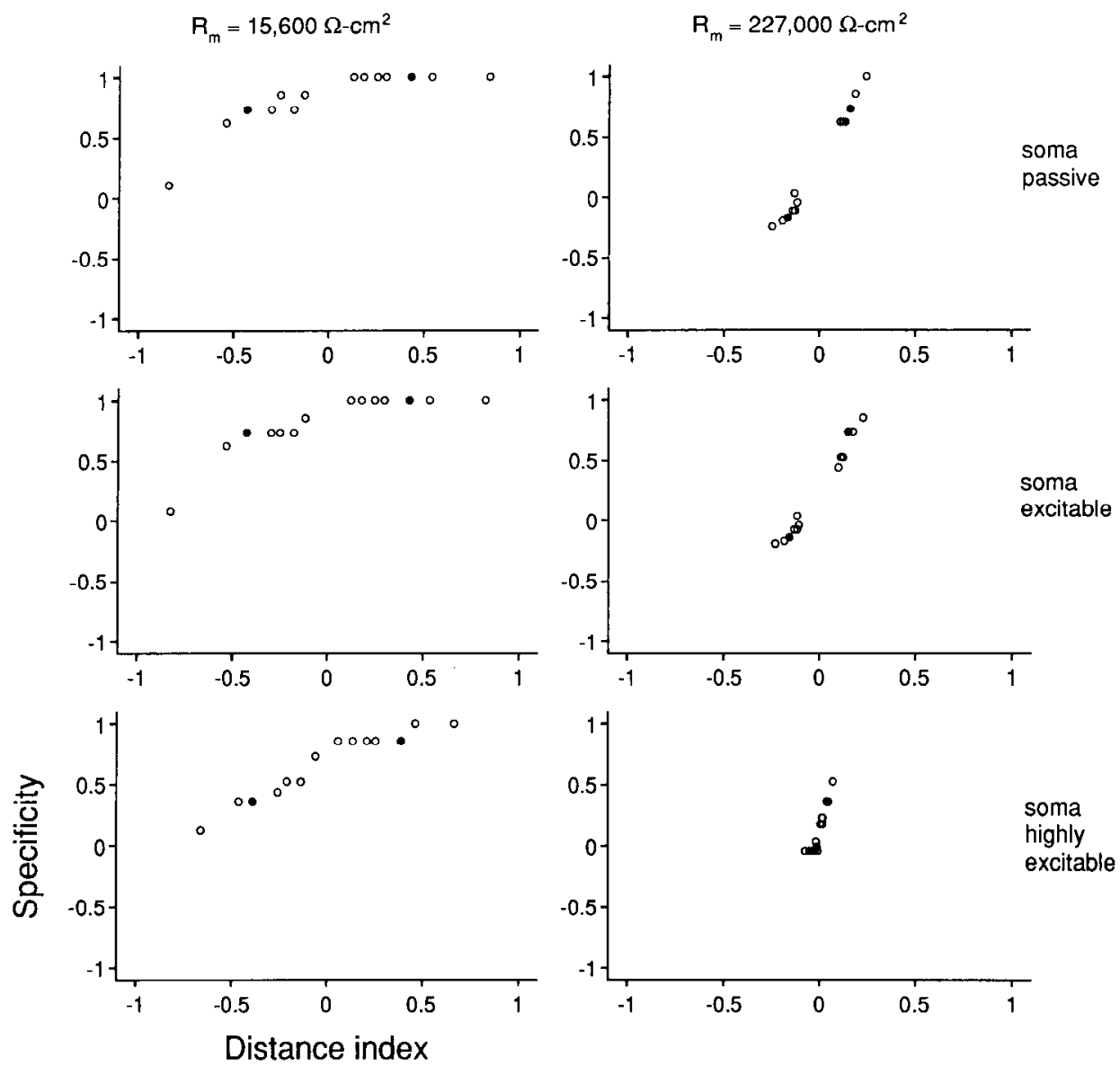

ponent of E-S potentiation in CAl is not blocked by doses of NMDA receptor blockers sufficient to block synaptic LTP and the late, heterosynaptic E-S potentiation (Reymann et al., 1989). In CA1 pyramidal cells, local exogenous application of glutamate paired with low-frequency synaptic stimulation increases the probability of firing with no significant effect on the EPSP (Hvalby et al., 1987). Depletion of either norepinephrine (NE) or 5-HT reduces synaptic LTP in dentate granule cells, but only 5-HT depletion affects E-S potentiation (Bliss et al., 1983). In dentate granule cells, E-S potentiation occurs at a higher threshold than does synaptic LTP (Kairiss et al., 1987). Finally, Douglas and Goddard (1975) found that, over a time course of many days, potentiation of the population spike decays to baseline, while potentiation of the EPSP persists.

Taken together, these findings suggest that E-S potentiation results from at least two distinct mechanisms: (1) a change in the ratio of excitation to feedforward inhibition and (2) an increase in the intrinsic excitability of the postsynaptic neuron. E-S potentiation by the first mechanism will always be specific, since it is just a manifestation of synaptic LTP, which is known to be homosynaptic in CAl (Brown et al., 1988). Indeed, the major objection to the second mechanism is that it would result in heterosynaptic LTP, which is not observed in CA1 (Wilson et al., 1981; Abraham et al., 1987). Heterosynaptic E-S potentiation has been seen, however, in the dentate gyrus (Abraham et al., 1985), and a peculiar, slowly developing heterosynaptic E-S potentiation has recently been observed in CA1 (Frey et al., 1988; Reymann et al., 1989).
Our results show that E-S potentiation by changes in excitability can appear to be homosynaptic if the untetanized input is sufficiently close to the soma, relative to the tetanized input (Figs. 6-9). This specificity is even greater if the hot spots are localized to the sites of the tetanized synaptic contacts (compare Figs. 6, 7), especially when the tetanized and untetanized inputs are segregated to completely separate primary dendrites (compare Figs. 6,8 ). Such localization might occur if the activation of the hot spots results from a biochemical reaction triggered in the potentiated spine.

One candidate for such a process is the activation of protein kinase $\mathrm{C}(\mathrm{PKC})$, which is believed to play a role in the synaptic component of LTP (reviewed by Brown et al., 1988; but see also Muller et al., 1988). Activation of this enzyme can upregulate or unmask voltage-sensitive $\mathrm{Ca}^{2+}$ channels in invertebrate preparations (Farley and Auerbach, 1986; Strong et al., 1987) and in cultured hippocampal neurons (Madison, 1989). There is also evidence that activation of PKC can increase excitability by blocking chloride (Madison et al., 1986) and $\mathrm{Ca}^{2+}$-activated $\mathrm{K}^{+}$conductances (Baraban et al., 1985) in hippocampal neurons. Such changes could contribute to the decrease in spike rate adaptation that sometimes accompanies LTP (Chavez-Noriega et al., 1990), although the slow $\mathrm{Ca}^{2+}$-activated $\mathrm{K}^{+}$current underlying the afterhyperpolarization is apparently not affected (Chavez-Noriega et al., 1989, 1990). Direct injection of active PKC into CA1 pyramidal cells potentiates the EPSP and increases the probability of firing, sometimes to the extent that two or three spikes are elicited by a single EPSP ( $\mathrm{Hu}$ et al., 


$$
R_{m}-15,600 \Omega \mathrm{cm}^{2}
$$
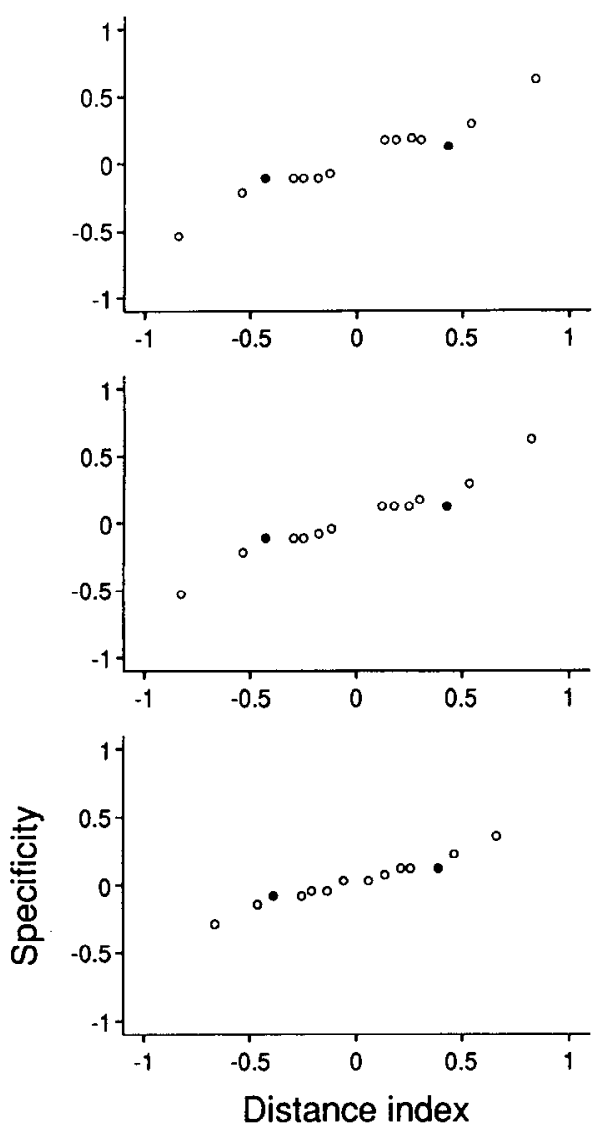

$R_{m}=227,000 \Omega-\mathrm{cm}^{2}$
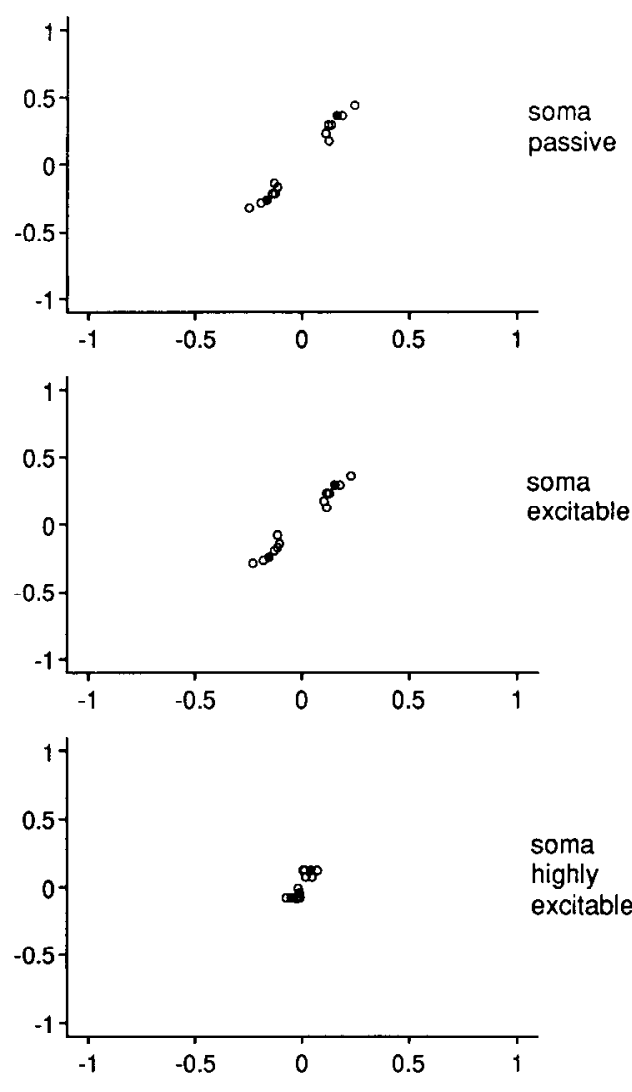

Figure 9. Same as Figure 8, except that the hot spots were added to the most proximal $80 \mu \mathrm{m}$ of the five primary dendrites, rather than to the sites of the tetanized synaptic contacts. E-S potentiation is nonspecific over a wide range of distance index values. It does show some specificity, however, when the untetanized input is sufficiently close to the soma relative to the tetanized input.
1987). Finally, polymyxin-B (a PKC inhibitor) blocks the late, heterosynaptic component of E-S potentiation in CA l, although the early component is unaffected (Reymann et al., 1988).

Other second messenger systems and neuromodulators could contribute to E-S potentiation. NE potentiates the population spike in CA1 with no effect on the EPSP (Mueller et al., 1981). The effect is via $\beta$-receptors and decays with a half-time of about $2 \mathrm{hr}$ following washout of the agonist (Dunwiddie and Thomas, 1990; Taylor et al., 1990). Gray and Johnston (1987) report that $\mathrm{NE}$ increases the amplitude of whole-cell $\mathrm{Ca}^{2+}$ currents, and the mean fractional open time for single $\mathrm{Ca}^{2+}$ channel openings, in dentate granule cells; these effects are mimicked by cAMP. In preliminary experiments in CAl, L. E. Chavez-Noriega and C. F. Stevens (personal communication; see also Chavez-Noriega and Bliss, 1991) have found that 8-bromo-cAMP causes leftward shifts in the E-S relation and reduces tetanus-induced E-S potentiation. Cholinergic drugs can also mimic E-S potentiation, although these effects do not persist after washout (Meffert et al., 1990).

Akaike and collaborators have recently found evidence of another mechanism by which tetanic stimulation could increase neuronal excitability (Takahashi et al., 1989; Akaike and Takahashi, 1990; and N. Akaike and K. Takahashi, personal communications). In acutely dissociated CA1 neurons, they have found a fast, TTX-sensitive $\mathrm{Ca}^{2+}$ current that increases threefold following direct tetanic current injection.

\section{Heterosynaptic $E-S$ potentiation in $C A I$}

Although E-S potentiation in our simulations are specific for some patterns of synaptic input, for others it was nonspecific, in some cases such that the effect on the untetanized input was actually greater than on the tetanized input. The results shown in Figure 10 suggest that this negative specificity is a consequence of the relatively greater sensitivity of more distal synapses to changes in dendritic excitability.

These results lead to an important prediction: if a significant component of E-S potentiation in CAl is caused by intrinsic changes in postsynaptic excitability, then that component should appear to be heterosynaptic if the control (untetanized) input is sufficiently far from the soma relative to the tetanized input.

Only a few previous studies have directly tested for heterosynaptic effects between proximal and distal synaptic inputs. Using the medial and lateral perforant path inputs to dentate granule cells, McNaughton and Barnes (1977) found no heterosynaptic potentiation of the EPSP. They did not, however, study E-S potentiation. Abraham et al. (1985) found heterosynaptic E-S potentiation of the proximal (medial perforant path) input to dentate granule cells following tetanization of the distal (lateral perforant path) input, but they did not report results of the reverse experiment. In CA3 pyramidal cells, tetanization of the proximal (mossy fiber) input causes heterosynaptic potentiation of the EPSP at the distal (commissural/associational) input, whereas tetanization of the distal input does not potentiate the proximal EPSP (Bradler and Barrionuevo, 1990). Whether there are similar heterosynaptic effects for E-S potentiation in CA3 is not known. Andersen et al. (1987) compared EPSP shapes and spike waveforms elicited via proximal and distal inputs to CA1 pyramidal cells, but they did not compare the effects of tetanizing these inputs.

One way to test our prediction in CA1 would be to use as the 


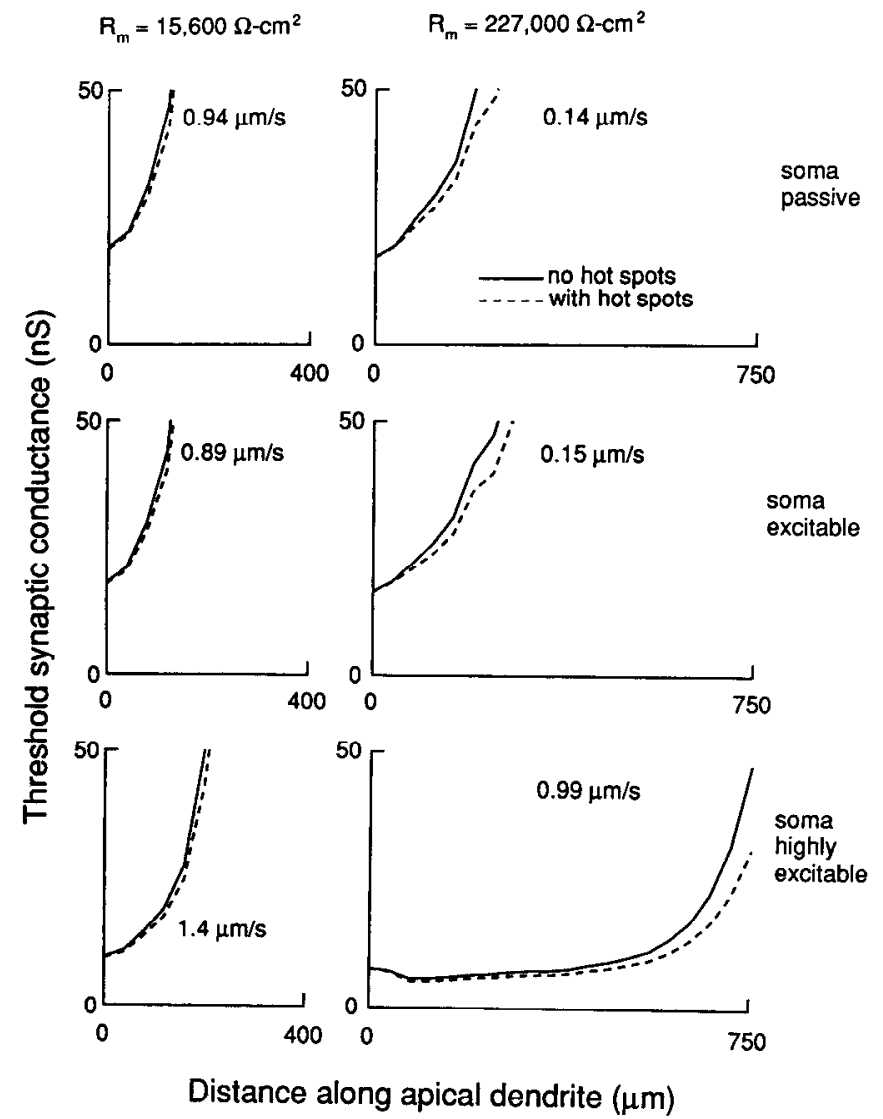

Figure 10. Synaptic strength just sufficient to fire the cell (given as peak synaptic conductance), as a function of the location of the synapse along the primary apical dendrite, for different membrane resistances and levels of excitability. For all but the highest values of these parameters the function approaches a vertical asymptote, beyond which a single synapse, regardless of its strength, cannot fire the cell. The addition of hot spots to the proximal dendrites (broken lines) caused a disproportionately greater reduction in threshold synaptic strength at the more distal locations. The strength of the hot spot, given as peak $\mathrm{Ca}^{2+}$ permeability in each of the 10 compartments with hot spots, appears on each graph.

control input fibers of the perforant path (which synapse on the distal apical dendrites of CA1 pyramidal cells) while using the more proximal Schaffer collaterals as the tetanized input. If heterosynaptic E-S potentiation were observed in such an experiment, it would give further support to the hypothesis that changes in postsynaptic excitability can contribute to E-S potentiation.

While this article was in review, we learned of two recent studies that are relevant. Hess and Gustafsson (1990) have discovered a prolonged, heterosynaptic potentiation of the field EPSP in CA1. This potentiation is associated with a leftward shift in the E-S relation and appears similar in form and magnitude to that shown for our simulated intracellular EPSP in Figure 4. It requires NMDA receptor activation for its induction and can be elicited in the presence of picrotoxin. The heterosynaptic effect cannot be seen when the control and tetanized inputs are segregated to apical and basal dendrites, respectively. This is consistent with our simulations of Figure 8, in which high specificity values were obtained with the inputs thus segregated. Chetkovich et al. (1991) report evidence that NMDA receptor activation increases the mean open time of high-threshold $\mathrm{Ca}^{2+}$ channels in CA1 pyramidal cells, via a $\mathrm{Ca}^{2+}$-dependent increase in cAMP, and suggest that this may be related to E-S potentiation.

\section{Appendix}

The membrane potential over the neuron was modeled using the cable equation (Rall, 1989). Hines (1984) describes in detail the finite-difference representation of this partial differential equation and his second-order implicit algorithm for its numerical integration.

In our model the ionic currents were

$$
\begin{aligned}
I_{L} & =g_{L}\left(V-E_{L}\right), \\
I_{\mathrm{Na}} & =\bar{g}_{\mathrm{Na}} m^{3} h\left(V-E_{\mathrm{Na}}\right), \\
I_{\mathrm{K}} & =\bar{g}_{\mathrm{K}} n^{4}\left(V-E_{\mathrm{K}}\right), \\
I_{\mathrm{Ca}} & =\bar{p}_{\mathrm{Ca}} s^{2} 2 F u\left(\left[\mathrm{Ca}^{2+}\right]_{i} \exp (u)-\left[\mathrm{Ca}^{2+}\right]_{o}\right) /(\exp (u)-1),
\end{aligned}
$$

where

$$
\begin{array}{rlrl}
u & =2 F V /(1000 R T), \\
T & =303.16^{\circ} \mathrm{K}, & & \\
\tilde{g}_{\text {na }} & =0.1 \mathrm{~S} / \mathrm{cm}^{2} & & \text { (in the axon), } \\
& =4.0 \mathrm{~S} / \mathrm{cm}^{2} & & \text { (in the axon initial segment), } \\
\bar{g}_{\mathrm{K}} & =0.12 \mathrm{~S} / \mathrm{cm}^{2} & & \text { (in the axon), } \\
& =2.0 \mathrm{~S} / \mathrm{cm}^{2} & & \text { (in the axon initial segment), } \\
E_{\mathrm{Na}} & =+45 \mathrm{mV}, & & {\left[\mathrm{Ca}^{2+}\right]_{i}=50 \mathrm{nM},} \\
E_{\mathrm{K}} & =-90 \mathrm{mV}, & & {\left[\mathrm{Ca}^{2+}\right]_{o}=2 \mathrm{mM} .}
\end{array}
$$

The potential difference across the membrane, $V$, is in millivolts, and $F$ and $R$ are the Faraday and gas constants, respectively. The leakage conductance, $g_{L}$, is the reciprocal of the specific membrane resistance, $R_{m}$, which varied from 15,600 to $227,000 \Omega \cdot \mathrm{cm}^{2}$ as indicated in Results. The leakage equilibrium potential, $E_{L}$, was adjusted to give a resting potential of -70 $\mathrm{mV}$. Its value ranged from $-70 \mathrm{mV}$ in passive compartments to $-86.7 \mathrm{mV}$ in the axon initial scgment $\left(R_{m}=227,000 \Omega \cdot \mathrm{cm}^{3}\right)$. The peak $\mathrm{Ca}^{2+}$ channel permeability, $\tilde{p}_{\mathrm{Ca}}$, is the hot spot strength, which varied in different simulations as described in Results.

The variables $m, h, n$, and $s$ are gating variables in the formalism of Hodgkin and Huxley (1952). Each is determined by a differential equation of the form

$$
\frac{d m}{d t}=\alpha_{m}(1-m)-\beta_{m} m,
$$

where the transition rates $\alpha$ and $\beta$ are functions of membrane potential:

$$
\begin{aligned}
\alpha_{m} & =-0.32(V+52) /(\exp (-(V+52) / 4)-1), \\
\beta_{m} & =0.26(V+25) /(\exp ((V+25) / 5)-1), \\
\alpha_{h} & =0.128 \exp (-(V+48) / 18), \\
\beta_{h} & =4 /(\exp (-(V+25) / 5)+1), \\
\alpha_{n} & =-0.016(V+50) /(\exp (-(V+50) / 5)-1), \\
\beta_{n} & =0.25 \exp (-(V+55) / 40), \\
\alpha_{s} & =-0.05(V+40) /(\exp (-(V+40) / 10)-1), \\
\beta_{s} & =2 \exp (-(V+65) / 18) .
\end{aligned}
$$




\section{References}

Abraham WC, Bliss TVP, Goddard GV (1985) Heterosynaptic changes accompany long-term but not short-term potentiation of the perforant path in the anaesthetized rat. J Physiol (Lond) 363:335-349.

Abraham WC, Gustafsson B, Wigström H (1987) Long-term potentiation involves enhanced synaptic excitation relative to synaptic inhibition in guinea-pig hippocampus. J Physiol (Lond) 394:367-380.

Akaike N, Takahashi K (1990) Asymmetrical regional distribution of tetrodotoxin-sensitive calcium-conducting channels in the rat hippocampus. Soc Neurosci Abstr 16:676.

Andersen P, Sundberg SH, Sveen O, Swann JW Wigström H (1980) Possible mechanisms for long-lasting potentiation of synaptic transmission in hippocampal slices from guinea-pigs. J Physiol (Lond) 302: 463-482.

Andersen P, Storm J, Wheal HV (1987) Thresholds of action potentials evoked by synapses on the dendrites of pyramidal cells in the rat hippocampus in vitro. J Physiol (Lond) 383:509-526.

Baraban JM, Snyder S, Alger BE (1985) Protein kinase C regulates ionic conductance in hippocampal pyramidal neurons: electrophysiological effects of phorbol esters. Proc Natl Acad Sci USA 82:25382542.

Bekkers JM, Stevens CF (1989) NMDA and non-NMDA receptors are co-localized at individual excitatory synapses in cultured rat hip pocampus. Nature 341:230-233.

Bliss TVP, Lømo T (1973) Long-lasting potentiation of synaptic transmission in the dentate area of the anaesthetized rabbit following stimulation of the perforant path. J Physiol (Lond) 232:331-356.

Bliss TVP, Goddard GV, Riives M (1983) Reduction of LTP in the dentate gyrus of the rat following selective depletion of monoamines. J Physiol (Lond) 334:475-491.

Bradler JE, Barrionuevo G (1990) Heterosynaptic correlates of longterm potentiation induction in hippocampal CA3 neurons. Neuroscience 35:265-271.

Brown TH, Wong RKS, Prince DA (1979) Spontaneous miniature synaptic potentials in hippocampal neurons. Brain Res 177:194-199.

Brown TH, Fricke RA, Perkel DH (1981) Passive electrical constants in three classes of hippocampal neurons. J Neurophysiol 46:812-827.

Brown TH, Chapman PF, Kairiss EW, Keenan CL (1988) Long-term synaptic potentiation. Science 242:724-728.

Chave $<$-Noriega LE, Bliss TVP (1991) Persistent modulation of neural excitability in the hippocampus: the role of EPSP-spike (E-S) potentiation. In: Glutamate, cell death and memory (Asher P, Choi D, Christen P, eds), pp 37-44. Heidelberg: Springer.

Chavez-Noriega LE, Bliss TVP, Halliwell JV (1989) The EPSP-spike (E-S) component of long-term potentiation in the rat hippocampal slice is modulated by GABAergic but not cholinergic mechanisms. Neurosci. Lett 104:58-64.

Chavez-Noriega LE, Halliwell JV, Bliss TVP (1990) $\Lambda$ decrease in firing threshold observed after induction of the EPSP-spike (E-S) component of long-term potentiation in rat hippocampal slices. Exp Brain Res 79:633-641.

Chetkovich DM, Gray R, Johnston D, Sweatt JD (1991) $N$-methylD-aspartate receptor activation increases cAMP levels and voltagegated $\mathrm{Ca}^{2+}$ channel activity in area $\mathrm{CAl}$ of hippocampus. Proc Natl Acad Sci USA 88:6467-6471.

Douglas RM, Goddard GV (1975) Long-term potentiation of the perforant path-granule cell synapse in the rat hippocampus. Brain Res 86:205-215.

Dunwiddie TV, Thomas LR (1990) Long-term increases in the evoked population spike in the CA1 region of rat hippocampus induced by beta-adrenergic receptor activation. Soc Neurosci Abstr 16:653.

Edwards FA, Konnerth A, Sakmann B, Takahashi T (1989) A thin slice preparation for patch clamp recordings from neurones of the mammalian central nervous system. Pfluegers Arch 414:600-612.

Fan P, O'Regan PA, Szerb JC (1988) Effect of low glucose concentration on synaptic transmission in the rat hippocampal slice. Brain Res Bull 21:741-747.

Farley J, Auerbach S (1986) Protein kinase C activation induces conductance changes in Hermissenda photoreceptors like those seen in associative learning. Nature 319:220-223.

Fisher RE, Gray R, Johnston D (1990) Properties and distribution of single voltage-gated calcium channels in adult hippocampal neurons. J Neurophysiol 64:91-104.

Frey U, Krug M, Reymann KG, Matthies H (1988) Anisomycin, an inhibitor of protein synthesis, blocks late phases of LTP phenomena in the hippocampal CAl region in vitro. Brain Res 452:57-65.

Gray R, Johnston D (1987) Noradrenaline and beta-adrenoceptor agonists increase activity of voltage-dependent calcium channels in hippocampal neurons. Nature 327:620-622.

Griffith WH, Brown TH, Johnston D (1986) Voltage-clamp analysis of synaptic inhibition during long-term potentiation in hippocampus. J Neurophysiol 55:767-775.

Haas HL, Rose G (1982) Long-term potentiation of excitatory synaptic transmission in the rat hippocampus: the role of inhibitory processes. J Physiol (Lond) 329:541-552.

Haas HL, Rose G (1984) The role of inhibitory mechanisms in hippocampal long-term potentiation. Neurosci Lett 47:301-306.

Hagiwara S, Byerly L (1981) Calcium channel. Annu Rev Neurosci $4: 69-125$

Hess G, Gustafsson B (1990) Changes in field excitatory postsynaptic potential shape induced by tetanization in the CAl region of the guinea-pig hippocampal slice. Neuroscience 37:61-69.

Higashima M, Sawada S, Yamamoto C (1986) A revised method for generation of unitary postsynaptic potentials for quantal analysis in the hippocampus. Neurosci Lett 68:221-226.

Hille B (1984) Ion channels of excitable membranes. Sunderland, MA: Sinauer.

Hines M (1984) Efficient computation of branched nerve equations. Int J Biomed Comput 15:69-76.

Hines $M$ (1989) A program for simulation of nerve equations with branching geometries. Int J Biomed Comput 24:55-68.

Hodgkin AL, Huxley AF (1952) A quantitative description of membrane current and its application to conduction and excitation in nerve. J Physiol (Lond) 117:500-544.

Hodgkin AL, Katz B (1949) The effect of sodium ions on the electrical activity of the giant axon of the squid. J Physiol (Lond) 108:37-77.

Hu GY, Hvalby O, Walaas I, Albert KA, Skjeflo P, Andersen P, Greengard $P$ (1987) Protein kinase $C$ injection into hippocampal pyramidal cells elicits features of long term potentiation. Nature 328:426429.

Hvalby O, Lacaille JC, Hu GY, Andersen P (1987) Postsynaptic longterm potentiation follows coupling of dendritic glutamate application and synaptic activation. Experientia 43:599-601.

Jack JJB, Noble D, Tsien RW (1975) Electric current flow in excitable cells. Oxford: Clarendon.

Johnston D, Brown TH (1983) Interpretation of voltage-clamp measurements in hippocampal neurons. J Neurophysiol 50:464-486.

Kairiss EW, Abraham WC, Bilkey DK, Goddard GV (1987) Field potential evidence for long-term potentiation of feed-forward inhibition in the rat dentate gyrus. Brain Res 401:87-94.

Lecar H, Nossal R (1971) Theory of threshold fluctuations in nerves. I. Relationships between electrical noise and fluctuations in axon firing. Biophys J 11:1048-1067.

Llinás RR (1988) The intrinsic electrophysiological properties of mammalian neurons: insights into central nervous system function. Science 242:1654-1664.

Lømo T (1971a) Patterns of activation in a monosynaptic cortical pathway: the perforant path input to the dentate area of the hippocampal formation. Exp Brain Res 12:18-45.

Lomo T (1971b) Potentiation of monosynaptic EPSPs in the perforant path-dentate granule cell synapse. Exp Brain Res 12:46-63.

Madison DV (1989) Phorbol esters increase unitary calcium channel activity in cultured hippocampal neurons. Soc Neurosci Abstr 15:16.

Madison DV, Malenka RC, Nicoll RA (1986) Phorbol esters block a voltage-sensitive chloride current in hippocampal pyramidal cells. Nature 321:695-697.

McNaughton BL, Barnes CA (1977) Physiological identification and analysis of dentate granule cell responses to stimulation of the medial and lateral perforant pathways in the rat. J Comp Neurol 175:439 454.

Meffert MK, Cohen GA, Madison DV (1990) Cholinergic modulation of E-S coupling in CAl pyramidal cells of the rat hippocampus. Soc Neurosci Abstr 16:1055.

Mueller AL, Hoffer BJ, Dunwiddie TV (1981) Noradrenergic responses in rat hippocampus: evidence for mediation by $\alpha$ and $\beta$ receptors in the in vitro slice. Brain Res 214:113-126.

Muller D, Turnbull J, Baudry M, Lynch G (1988) Phorbol esterinduced synaptic facilitation is different than long-term potentiation. Proc Natl Acad Sci USA 85:6997-7000. 
Press WH, Flannery BP, Teukolsky SA, Vetterling WT (1988) Numerical recipes in C. Cambridge: Cambridge UP.

Rall W (1989) Cable theory for dendritic neurons. In: Methods in neuronal modeling: from synapses to networks (Koch C, Segev I, eds), pp 9-62. Cambridge, MA: MIT Press.

Regehr WG, Tank DW (1990) Postsynaptic NMDA receptor-mediated calcium accumulation in hippocampal CA1 pyramidal cell dendrites. Nature 345:807-810.

Regehr WG, Connor JA, Tank DW (1989) Optical imaging of calcium accumulation in hippocampal pyramidal cells during synaptic activation. Nature 341:533-536.

Reymann KG, Frey U, Jork R, Matthies H (1988) Polymyxin B, an inhibitor of protein kinase $C$, prevents the maintenance of synaptic long-term potentiation in hippocampal CAl neurons. Brain Res 440 : 305-314.

Reymann KG, Matthies HK, Schulzeck K, Matthies H (1989) $N$-methyl-D-aspartate receptor activation is required for the induction of both early and late phases of long-term potentiation in rat hippocampal slices. Neurosci Lett 96:96-101.

Schwartzkroin PA, Webster K (1975) Long lasting facilitation of a synaptic potential following tetanization in the in vitro hippocampal slice. Brain Res 89:107-119.

Strong JA, Fox AP, Tsien RW, Kaczmerak LK (1987) Stimulation of protein kinase C recruits covert calcium channels in Aplysia bag cell neurons. Nature 325:714-717.

Takahashi K, Wakamori M, Akaike N (1989) Hippocampal CA1 pyramidal cells of rats have four voltage-dependent calcium conductances. Neurosci Lett 104:229-234.

Taube JS, Schwart7kroin PA (1987) Intracellular recording from hippocampal CA1 interneurons before and after development of longterm potentiation. Brain Res 419:32-38.
Taube IS, Schwartzkroin PA (1988a) Mechanisms of long-term potentiation: EPSP/spike dissociation, intradendritic recordings, and glutamate sensitivity. J Neurosci 8:1632-1644.

Taube JS, Schwartzkroin PA (1988b) Mechanisms of long-term potentiation: a current-source density analysis. J Neurosci 8:1645-1655.

Taylor M, Dunwiddie TV, Proctor WR (1990) Cellular mechanisms underlying long-term beta-adrenergically mediated potentiation in the CA1 region of rat hippocampus. Soc Neurosci Abstr 16:653.

Traub RD (1982) Simulation of intrinsic bursting in CA3 hippocampal neurons. Neuroscience 7:1233-1242.

Turner DA (1984a) Segmental cable evaluation of somatic transients in hippocampal neurons (CA1, CA3, and dentate). Biophys J 46:7384.

Turner DA (1984b) Conductance transients onto dendritic spines in a segmental cable model of hippocampal neurons. Biophys J 46:8596.

Turner DA (1988) Waveform and amplitude characteristics of evoked responses to dendritic stimulation of $\mathrm{CA} 1$ guinea-pig pyramidal cells. J Physiol (Lond) 395:419-439.

Wathey JC, Chattarii S, Lytton WW, Jester JM, Sejnowski TJ (1991) Computer simulations of E-S potentiation in hippocampal CA1 pyramidal cells. Soc Neurosci Abstr 17:385.

Wilson R (1981) Changes in translation of synaptic excitation to dentate granule cell discharge accompanying long-term potentiation. $I$. Differences between normal and reinnervated dentate gyrus. J Neurophysiol 46:324-338.

Wilson R, Levy WB, Steward O (1981) Changes in translation of synaptic excitation to dentate granule cell discharge accompanying long-term potentiation. II. An evaluation of mechanisms utilizing dentate gyrus dually innervated by surviving ipsilateral and sprouted crossed temporodentate inputs. J Neurophysiol 46:339-355. 